\title{
The Conceptual Chain From Event Activities to Emotions to Atmosphere, and Sponsor Awareness and Patronage
}

\author{
T. Bettina Cornwell, Steffen Jahn, and Wang Suk Suh
}

\begin{abstract}
Sport, arts, and cause events are a service product in their own right and also often a platform for the marketing of other products. Emotions are recognized as important both in marketing of the event (attendance and future attendance) and marketing of products via the event. When positive emotions prevail, this can influence both future attendance as well as responses to sponsorship. This study examines the role of emotions and atmosphere at an international track and field event. Mediated regression results show that event activities support positive emotions and in turn the development of a good atmosphere; the resulting atmosphere influences both sponsor awareness and future patronage in a positive way. As well, event activities hold a direct positive influence on sponsor awareness.
\end{abstract}

T.B. Cornwell $(\bowtie) \bullet$ W.S. Suh

University of Oregon, Eugene, OR, USA

e-mail: tbc@uoregon.edu; wsuh@uoregon.edu

S. Jahn

University of Goettingen, Goettingen, Germany

e-mail: steffen.jahn@wiwi.uni-goettingen.de

L. Petruzzellis, R.S. Winer (eds.), Rediscovering the Essentiality of Marketing, Developments in Marketing Science: Proceedings of the Academy of Marketing Science, DOI 10.1007/978-3-319-29877-1_155 